\title{
Programmed Ventricular Stimulation in the Management of Brugada Syndrome Patients
}

\author{
Mauricio Ibrahim Scanavacca ${ }^{\circledR}$ and Denise Tessariol Hachul \\ Instituto do Coração (Incor), São Paulo, SP - Brazil
}

Since 1980, the American College of Cardiology (ACC) and the American Heart Association (AHA), by means of a systematic methodology, have incorporated and adapted scientific evidence into practical recommendations aiming to improve preventive and therapeutic measures for cardiovascular diseases. These guidelines have become the current reference for cardiology practices and been adopted by many societies, which adapt them according to local realities. ${ }^{1}$

In 2006, the AHA/ACC, together with the Heart Rhythm Society (HRS), published the first guidelines for the management of patients with ventricular arrhythmias and prevention of sudden death (SD). In 2017, this first document was updated by the same societies and published in October 2018.2,3

Despite considerable advances in knowledge of risk stratification, prevention and treatment of SD, many gaps in its understanding still exist. Among many issues raised by the authors of the last review, two were addressed by an independent commission and recently published in an additional document. ${ }^{4}$

One of the issues is the subject of the present editorial and refers to the role of the electrophysiological study in risk stratification of asymptomatic patients with Brugada syndrome $(\mathrm{BrS})$.

$\mathrm{BrS}$ was described in 1992 in individuals with structurally normal hearts who had recovered from a cardiac arrest from ventricular fibrillation showing a unique electrocardiographic pattern, characterized by a right bundle-branch block with ST-segment elevation in the right precordial leads V1 -V3. ${ }^{5}$

In the last 25 years, several clinical studies have shown that the $\mathrm{BrS}$ is a genetically determined disease, affecting one in 2,000 - 10,000 individuals with apparently normal hearts. The risk of SD is knowingly high in patients who had already had arrhythmic syncope or had recovered from cardiac arrest. There is a consensus that implantation of an automated implantable cardioverter defibrillator (ICD) is the most effective method to prevent SD in these patients. ${ }^{6}$

On the other hand, the risk of SD is apparently low in asymptomatic BrS patients, which makes the decision-making

\section{Keywords}

Brugada Syndrome; Tachycardia, Ventricular; Ventricular Fibrillation; Death, Sudden, Cardiac/prevention \& control; Risk Factors; Defibrilators, Implantable/utilization.

\section{Mailing Address: Mauricio Ibrahim Scanavacca}

Av. Joaquim C. A. Marques, 1205. Postal Code 05688-021, Morumbi, SP - Brazil E-mail: mibrahim@cardiol.br, mauricio.scanavacca@gmail.com

DOI: $10.5935 / a b c .20190047$ about the use of ICD in these patients difficult. Besides, most of these patients are young and at risk of receiving inappropriate shocks, and experience technical problems with generators and electrodes over the years. ${ }^{7}$

Several clinical, familial, electrophysiological and genetic aspects have been investigated in attempt to determine the risk of SD in asymptomatic individuals with $\mathrm{BrS}$, who may benefit from an early ICD implantation. However, the discriminating ability of these methods is still a matter of controversy. ${ }^{6,8}$

Sustained ventricular tachycardia (SVT) induced by programmed ventricular stimulation (PVS) has been used for many years to identify patients at risk of spontaneous occurrence of SVT/ventricular fibrillation (VF) in patients with structural heart diseases, who may benefit from a prophylactic use of ICD. ${ }^{2,3}$ This approach was based on the efficacy of the method in reproducing SVT in a laboratory setting. ${ }^{9}$

Clinical observations have revealed that the capacity of the planned ventricular stimulation in reproducing ventricular arrhythmias, particularly SVT, is very high in the chronic phase of myocardial infarction, lower in non-ischemic heart diseases, and almost absent in cardiac channelopathies. ${ }^{2,3,9}$ This distinctive behavior is explained by characteristics of the arrhythmogenic substrate in sustained ventricular arrhythmias. In structural heart diseases, it depends on reentries into stable anatomic substrates, mostly represented by scars caused by diseases. Conditions that cause dense myocardial scars with preserved myocardial tissue channels favor the occurrence of reproducible SVTs. In contrast, EP has low reproducibility in conditions where these characteristics are not present. ${ }^{9}$

Therefore, the initial suggestion of using PVS for risk stratification of SD in patients with $\mathrm{BrS}$ caused surprise among traditional electrophysiologists, ${ }^{10}$ since $\mathrm{BrS}$ was until then considered a channelopathy without anatomic substrate based on gadolinium-enhanced magnetic resonance. Subsequent studies revealed that BrS patients have an arrhythmogenic substrate characterized, by invasive electrophysiological mapping, by late electrical potential, identified predominantly in subepicardial fibers in the right ventricular outflow tract. ${ }^{11}$

Although in some cases, these electrical features have been associated with persistent anatomical changes, ${ }^{12}$ in most of the cases, electrophysiologic changes are transient, modulated or induced by hormonal, autonomic, metabolic and drug-related conditions. ${ }^{6}$

This could explain why patients with persistent, spontaneous type 1 Brugada electrocardiographic pattern have higher risk of events compared with patients in whom the BrS pattern occurs occasionally. ${ }^{5}$ The possible explanation for that is the fact that, in the former patients, the arrhythmogenic substrate is more extensive and stable, detectable in the ECG, and thereby more suitable to SVT and VF in external modulation, 
whereas in the second condition, a milder substrate would be found, and hence the possibility of malignant arrhythmias would be lower, detected only in very special conditions. In this case, the substrate would be only identified by analysis of electrograms obtained from the epicardial surface or by infusion of potent sodium-channel blockers.

In line with this hypothesis, recent studies on radiofrequency catheter ablation of the subepicardial substrate in $\mathrm{BrS}$ have shown that the induction of SVT or VF is common in patients with spontaneous type 1 pattern; these arrhythmias became noninducible after ablation of the arrhythmogenic substrate with normalization of the typical pattern. ${ }^{11,13}$ The extension of the $\mathrm{BrS}$ substrate at the moment of the ES could then explain the differences in the results reported in several clinical studies and current controversies. ${ }^{14}$

Therefore, patients with BrS recovered from cardiac arrest or patients with persistent type 1 electrocardiographic pattern would have a higher rate of induction of ventricular arrhythmias as compared with those without electrocardiographic manifestations. However, so far, there is not enough information regarding the EKG presentation at the time of the electrophysiological study. ${ }^{15}$

The first study to use programmed ventricular stimulation for screening of asymptomatic BrS patients for ICD implantation involved 252 patients; 116 of them had a history of syncope or had recovered from cardiac arrest, and 136 were asymptomatic at diagnosis. Polymorphic ventricular tachycardia or VF were induced in 130 (51\%) patients. induction of ventricular arrhythmias was more frequent (73\%) in sympomtatic than asymptomatic $(33 \%)$ patients $(p=0.0001)$. Spontaneous arrhythmic event occurred in 52 individuals (21\%) in a mean follow-up of $34 \pm$ months, 45 (39\%) of 116 symptomatic patients and 7 (5\%) of 136 asymptomatic patients. On the other hand, only 1 patient in 91 (1.1\%) of the asymptomatic group presented spontaneous arrhythmic event when the ventricular pacing was negative..$^{15}$

These data were corroborated by a second study by the same group, in which patients were followed for up to 20 years. Induction of SVT/VF in the ES had a sensitivity of $75 \%$ and specificity of $91.3 \%$ for spontaneous occurrence of malignant arrhythmias in asymptomatic patients. Despite the low positive predictive value $(18.2 \%)$, the procedure had a negative predictive value of $98.3 \%{ }^{16}$

\section{References}

1. Halperin JL, Levine GN, Al-Khatib SM, Birtcher KK, Bozkurt B, Brindis $\mathrm{RG}$, et al. Further evolution of the ACC/AHA clinical practice guideline recommendation classification system: a report of the American College of Cardiology Foundation/American Heart Association Task Force on Clinical Practice Guidelines. J Am Coll Cardiol. 2016;67(13):1572-4.

2. European Heart Rhythm Association; Heart Rhythm Society, Zipes DP, Camm AJ, Borggrefe M, Buxton AE, et al. ACC/AHA/ESC 2006 guidelines for management of patients with ventricular arrhythmias and the prevention of sudden cardiac death: a report of the American College of Cardiology/ American Heart Association Task Force and the European Society of
Clinical studies by other authors did not reproduce these findings, generating a debate that persists up to the present days. The PRELUDE was a multicenter prospective study including 273 asymptomatic patients. During the clinical follow-up, with a median of 34 months, there was no significant difference in the rates of events between patients with and without induced ventricular arrhythmias in the ES. ${ }^{17}$ In the FINGER BrS registry involving 654 asymptomatic patients, followed by 31.9 (14 to 54.4 ) months, there was a low rate of events (0.5\%). Although this rate was higher in patients with induced ventricular arrhythmias in the ES, there was no statistical significance in the multivariate analysis. ${ }^{18}$

In the meta-analysis by Kusumoto et al., ${ }^{2}$ organized by the $\mathrm{AHA} / \mathrm{ACC} / \mathrm{HRS}$, six studies on $\mathrm{BrS}$ patients were selected of a total of 236 titles retrieved from traditional databases. To minimize possible patient overlap, the primary analysis included five of six studies selected, with exclusion of one study conducted in the same institution. Of 1,138 patients included, SVT or sustained VF was induced in 390 (34.3\%) with occurrence of major arrhythmic events (SVT, VF, cardiac MS or appropriate ICD therapy) in 13 (3.3\%) patients, compared with 12 events $(1.6 \%)$ in 748 patients without induced arrhythmia, resulting in an odds ratio (OR) of 2.3 (95\%IC: 0.63-8.66; $p=0.2$ ).

A second analysis included all six studies, with potential data duplication. Of 1,401 patients, 481 (34.2\%) had SVT or VF induced in the ES. In patients with induced SVT/VF, there were 23 arrhythmic events (5.0\%), whereas among those without SVT/VF induction, 14 events occurred (1.5\%), resulting in an OR of 3.3 (95\% $\mathrm{Cl}: 1.03-10.4 ; \mathrm{p}=0.04)$.

Based on these data, the 2017 AHA/ACC/HRS guidelines issued a $2 \mathrm{~B}$ recommendation with level of evidence $\mathrm{B}$ for indication of ES to asymptomatic BrS patients, using less aggressive ventricular stimulation protocols when performed (up to two extrastimulation). ${ }^{2}$

In summary, these data do not establish the real role of SVT/VF induction in asymptomatic patients with BrS, probably due to the lack of homogeneity of samples and methods used in the studies. These data also indicate the need for prospective, multicenter studies involving a larger number of patients.
Cardiology Committee for Practice Guidelines (Writing Committee to Develop Guidelines for Management of Patients With Ventricular Arrhythmias and the Prevention of Sudden Cardiac Death). J Am Coll Cardiol. 2006;48(5):e247-346.

3. Al-Khatib SM, Stevenson WG, Ackerman MJ, Bryant WJ, Callans DJ, Curtis AB, et al. 2017 AHA/ACC/HRS Guideline for Management of Patients With Ventricular Arrhythmias and the Prevention of Sudden Cardiac Death: A Report of the American College of Cardiology/American Heart Association Task Force on Clinical Practice Guidelines and the Heart Rhythm Society.. J Am Coll Cardiol. 2018;72(14):e91-220. 


\section{Editorial}

4. Kusumoto FM, Bailey KR, Chaouki AS, Deshmukh AJ, Gautam S, Kim RJ, et al.. Systematic Review for the 2017 AHA/ACC/HRS Guideline for Management of Patients With Ventricular Arrhythmias and the Prevention of Sudden Cardiac Death: A Report of the American College of Cardiology/ American Heart Association Task Force on Clinical Practice Guidelines and the Heart Rhythm Society. J Am Coll Cardiol. 2018;72(14):1653-76.

5. Brugada P, Brugada J. Right bundle branch block, persistent ST segment elevation and sudden cardiac death: a distinct clinical and electrocardiographic syndrome. A multicenter report. J Am Coll Cardiol. 1992;20(6):1391-6.

6. Priori SG, Wilde AA, Horie M, Cho Y, Behr ER, Berul C, et al. HRS/EHRA/ APHRS expert consensus statement on the diagnosis and management of patients with inherited primary arrhythmia syndromes: document endorsed by HRS, EHRA, and APHRS in May 2013 and by ACCF, AHA, PACES, and AEPC in June 2013. Heart Rhythm. 2013;10(12):1932-63.

7. van Rees JB, de Bie MK, Thijssen J, Borleffs CJ, Schalij MJ, van Erven L. Implantation-related complications of implantable cardioverter-defibrillators and cardiac resynchronization therapy devices: a systematic review of randomized clinical trials. J Am Coll Cardiol. 2011;58(10):995-1000.

8. Takagi M, Yokoyama Y, Aonuma K, Aihara N, Hiraoka M, Japan Idiopathic Ventricular Fibrillation Study (J-IVFS) Investigators. Clinical characteristics and risk stratification in symptomatic and asymptomatic patients with Brugada syndrome: multicenter study in Japan. J Cardiovasc Electrophysiol. 2007;18(12):1244-51.

9. Buxton AE, Lee KL, DiCarlo L, Gold MR, Greer GS, Prystowsky EN, et al. Electrophysiologic testing to identify patients with coronary artery disease who are at risk for sudden death. Multicenter Unsustained Tachycardia Trial Investigators. N Engl J Med. 2000;342(26):1937-45.

10. Brugada P, Brugada R, Mont L, Rivero M, Geelen P, Brugada J. Natural history of Brugada syndrome: the prognostic value of programmed electrical stimulation of the heart. J Cardiovasc Electrophysiol. 2003;14(5):455-7.
11. Nademanee K, Veerakul G, Chandanamattha P, Chaothawee L, Ariyachaipanich A, Jirasirirojanakorn K, et al. Prevention of ventricular fibrillation episodes in Brugada syndrome by catheter ablation over the anterior right ventricular outflow tract epicardium. Circulation. 2011;123(12):1270-9

12. Nademanee K, Raju H, de Noronha SV, Papadakis M, Robinson L, Rothery S, et al. Fibrosis, connexin-43, and conduction abnormalities in the Brugada Syndrome. J Am Coll Cardiol. 2015;66(18):1976-86.

13. Pappone C, Brugada J, Vicedomini G, Ciconte G, Manguso F, Saviano M, et al. Electrical substrate elimination in 135 consecutive patients with Brugada Syndrome. Circ Arrhythm Electrophysiol. 2017;10(5):e005053.

14. Brugada J, Pappone C, Berruezo A, Vicedomini G, Manguso F, Ciconte G, et al. Brugada Syndrome phenotype elimination by epicardial substrate ablation. Circ Arrhythm Electrophysiol. 2015;8(6):1373-81 .

15. Brugada P, Geelen P, Brugada R, Mont L, Brugada J. Prognostic value of electrophysiologic investigations in Brugada Syndrome. J Cardiovasc Electrophysiol. 2001;12(9):1004-7.

16. Sieira J, Conte G, Ciconte G, de Asmundis C, Chierchia GB, Baltogiannis $\mathrm{G}$, et al. Prognostic value of programmed electrical stimulation in Brugada syndrome: 20 years experience. Circ Arrhythm Electrophysiol. 2015;8(4):777-84.

17. Priori SG, Gasparini M, Napolitano C, Della Bella P, Ottonelli AG, Sassone $B$, et al. Risk stratification in Brugada syndrome: results of the PRELUDE (PRogrammed ELectrical stimUlation preDictive valuE) registry. J Am Coll Cardiol. 2012;59(1):37-45.

18. Probst V, Veltmann C, Eckardt L, Meregalli PG, Gaita F, Tan HL, et al. Long-term prognosis of patients diagnosed with Brugada syndrome: results from the FINGER Brugada Syndrome Registry. Circulation. 2010;121(5):635-43. 